\title{
URBAN TRANSPORT AND WELLBEING: A Critical ANAlysis
}

\author{
Tim Schwanen \\ Transport Studies Unit \\ School of Geography and the Environment \\ University of Oxford \\ Email: $\underline{\text { tim.schwanen@ouce.ox.ac.uk }}$
}

Chapter to appear in:

Mladenović, M.N., Toivonen, T., Willberg, E., and Geurs, K. (Eds.). (2021) Transport in Human Scale Cities. Cheltenham: Edward Elgar Publishing. 
I just wanted to be recognized and remembered by my nephews, by my kids ... always be an example to someone, like many were for me, as a reference of good things for those growing up. At least that, do something nice for the people in the suburbs*, show the people that there are good things around here as well, there are some guys doing nice things here, right ... [I want to] transform them [by] showing a way out, even if they are in some sort of financial challenge, which is quite common [with] social inequality, and [that] you don't have to remain caught in consumerism, capitalism, right. Sometimes the guy wants to have that car anyway, he wants to have that car and there's no way to have it. You can be there walking and

doing good things, right, instead of doing the wrong thing to be able to have that car. And look out for the community as well, right. Because in a certain way to the same people [to whom] you said "we bring people to the streets and the streets become more secure", you are like the agents of well-being for that community, you are looking after the community, you are taking care of the community, occupy the streets to make them more attractive to everyone.

* peripheral, typically poor areas at considerable distance from São Paulo’s city centre

\section{INTRODUCTION}

Pedro ran a scheme of group jogs between and across peripheral, lower-class neighborhoods in São Paulo when he was interviewed for a research project about community initiatives to promote walking and cycling. Like many other leaders of initiatives in São Paulo and London that were studied, Pedro was driven by a vision of the good life, society, and city and (local) community (see Schwanen and Nixon, 2020 for details on the study and methodology). It is interviews with the likes of Pedro that have helped me realize that most of the conceptualizations of wellbeing in transport research are not as attuned to complexity, nuance and context as they might and perhaps should be. This shortcoming is particularly salient if research is concerned with the relationship between transport and wellbeing in cities characterized by sharp social and spatial inequalities, when disadvantaged groups are considered, and/or outside the global North. Understandings of what the good life is and how it might be achieved are central to transport in human-scale cities, and academic perspectives on wellbeing and its relationship with transport must be able to capture their full diversity and dynamism.

In this chapter I will elaborate a critique of the conceptual underpinnings of research on transport and wellbeing and point towards other ways of thinking about that relationship. I will selectively review existing transport literature, most of which works with hedonic conceptions of wellbeing that concentrate on satisfaction with life or travel or positive and negative emotions during mobility. Research adopting eudaimonic conceptions developed in psychology and focused on flourishing and fulfillment is also considered. I then identify several risks associated with deployment of these hedonic and eudaimonic conceptions in transport research and offer some suggestions for a context-sensitive and process-oriented approach to wellbeing in transport research. 


\section{DOMINANCE OF HEDONIC UNDERSTANDINGS}

The field of transport studies has long had an interest in the relationships between mobility and wellbeing. At least since the 1970s researchers have analyzed satisfaction with transport modes, often in the context of work on the links between travel behavior and attitudes (Recker and Golob, 1976; Dobson et al., 1978), or used measures of observed travel behavior and/or accessibility to understand inequalities in fulfillment of need and opportunities to lead a satisfying life (Cutler, 1975; Pas and Koppelman, 1986). In this century, there has been extensive interest in transport-related social exclusion (Lucas, 2012), and much of this work also touches on themes related to wellbeing.

It is only since the late 2000s that research is explicitly framed in terms of the relationship between subjectively experienced wellbeing and travel behaviour. Reviews of this research are available in De Vos et al. (2013), Mokhtarian (2019) and Chatterjee et al. (2020). Suffice to say that research in this vein tends to focus on individual experience and privilege hedonic over eudaimonic understandings of wellbeing.

The previously introduced hedonic/eudaimonic distinction is common in the interdisciplinary 'science of happiness' literature. Hedonic perspectives on wellbeing focus on the passions; they typically rely on the measurement of firstly satisfaction as a cognitive evaluation of an individual's experience of life in general or in specific domains, such as work or indeed travel, and secondly affective responses in terms of pleasure experienced and pain avoided (Diener, 2009). The Satisfaction with Travel Scale (STS), originally proposed by Ettema et al. (2011) and now widely used, exemplifies the hedonic perspective very well, as it merges the cognitive and affective dimensions in a nine-item construct. Also belonging to the hedonic category are travel behavior studies that examine the interrelations between feelings during specific trips and longer-term mood and satisfaction (Gärling, 2018; Le and Carrel, 2019), or that work with Kahneman et al.'s (1997) distinction between utility as anticipated outcomes of choice alternatives (decision utility) and utility as experiences of pleasure and pain (experienced utility) (Abou-Zeid and Ben-Akiva, 2012). Even studies using bio-markers, such as skin conductance, to measure stress while travelling in a pre-cognitive manner - that is, without recourse to asking people what they (thought they) felt and instead placing sensors on people's bodies (Texeira et al., 2020) - belong to the hedonic tradition. Whatever the method, wellbeing is taken to be a subjective state that individuals can move in and out of, depending on experienced action or choice.

The dominance of hedonic perspectives on wellbeing in the transport literature has multiple causes. One is their popularity in the science of happiness literature, another their proximity to the theoretical frameworks that prevail in transport research. The work of authors such as Abou-Zeid and Ben-Akiva builds on the venerable random utility theory tradition that has long been influential in transport engineering. The STS approach developed by Ettema and colleagues is also no radical departure from thinking and research praxis in transport research. Both lines of inquiry build on (tacit) understandings of travel behavior in their respective research communities. Linked to theoretical proximity is methodological continuity; psychometric measurement scales of hedonic wellbeing can be integrated relatively easily in the data collection instruments and procedures and econometric techniques that are widely used in transport research. Some of the early studies into the links between travel behavior and attitudes (Golob and Recker, 1976; Dobson et al., 1978) used ordinal scale satisfaction ratings of service attributes to evaluate different transport modes, while research on pedestrian facility level-of-service has complemented 'objective' measures with indicators of the level of satisfaction with a given facility study participants experienced (Khisty, 1994). Meanwhile, 
public transport research has for decades drawn on measures of user satisfaction informed by measures from marketing studies (Morton et al., 2016).

There has, however, been some experimentation with eudaimonic conceptions of wellbeing in transport research (Vella-Brodrick and Stanley, 2013; Singleton, 2019; Singleton, 2019; Cuignet et al., 2020). Eudaimonic perspectives come in different shapes and sizes but concentrate on self-fulfillment and flourishing (Waterman, 1993). They often go back to Aristotle for whom pleasure and enjoyment were vulgar pursuits. Happiness, for him, is the self-sufficient "end of all actions" that "makes life desirable and lacking in nothing" (Aristotle, 2009 [n.d.], page 11). Realizing individuals' daimon (the best in them), happiness is a state of being that makes people capable of political life in the polis. Aristotle also argues that happiness does not befall people but is a disposition to be achieved through the work (ergon) of virtuous action driven by rational thought. Aristotle defines multiple virtues, including temperance, friendliness and truthfulness, all of which hold the middle ground between excess and deficiency. Significantly, he limited the ability to achieve happiness through virtuous action to free men. While the resulting exclusion of women and slaves was normal in the Athens of his days, it also makes Aristotelian happiness a political state of being (Agamben, 2016).

Rather than engaging directly with Aristotle, transport researchers have relied more on the writings of contemporary psychologists (Ryan et al., 2008; Ryff and Singer, 2008) who have offered a very partial reading of the original works and typically ignore the politics of wellbeing in Aristotle's texts. As a result, transport research follows eudaimonic psychology in concentrating on the presence and attainment of constructs such as autonomy, positive relations, security, purpose in life, environmental mastery and personal growth. These are either imagined to coexist alongside hedonic wellbeing (Singleton, 2019; Cuignet et al., 2020) or act as precedents of hedonic wellbeing (Vella-Brodrick and Stanley, 2013; Ingvardson et al., 2020). For instance, Singleton (2019) uses survey data from Portland, OR to identify health, confidence, autonomy and security as eudaimonic constructs alongside the hedonic ones of enjoyment, attentiveness, distress, and fear and then correlates all of these with a series of travel behavior indicators in a structural equation model.

\section{RISKS AND ASSUMPTIONS}

Much can be said in favor of the above perspectives on wellbeing in relation to transport, both of which help us make sense of Pedro's narrative at the start of this chapter. Without overgeneralizing from a single case in a particular context, we can see from his reflections how moving around on foot can contribute to positive relations, environmental mastery and security for both the participants in Pedro's scheme and the inhabitants of the traversed neighborhoods. The jog group scheme also gives purpose in life and positive relations to Pedro himself. Hedonic conceptions of wellbeing are evident in his discussion of (male) youngsters chasing the satisfaction that car use/ownership can give (and the dubious pathways this may lead them on). The interview also suggests that, on the whole, Pedro was quite satisfied with what had been achieved.

At the same time, his words offer a more critically reflexive and socialized account of wellbeing than most transport research on wellbeing does. Not only does he discuss multiple social and socio-spatial relationships, he also refers to concrete individuals (his nephews and kids), categories ("people in the suburbs", "the guy",) and socialities ("the community") in specific places within São Paulo and positions them within the broader political economy context of consumerism and capitalism, known for the deep socio-spatial inequalities they 
engender. A hierarchy of wellbeing forms is emerging here, one that is not grounded in the writings of one of Antiquity's most well-known philosophers but in the effects on people's lives and urban communities generated by the pursuit of different forms of wellbeing (in a manner that goes beyond discussions in the eudaimonic psychology literature - e.g., Kasser et al. (2007); Richins (2017)). Pedro was certainly not the only participant in our study of community initiatives supporting walking and cycling in London and São Paulo to differentiate between 'wellbeings' in terms of the effects their pursuit generates.

Transport researchers can benefit from critical reflection on the effects that the pursuit of wellbeing generates. It can help them to come to grips with the challenging political dilemma from which researchers empirically probing the transport link tend to shy away (at least in their publications): is the pursuit of wellbeing in urban transport by some desirable if it marginalizes or disadvantages others? This question is particularly salient with, but not limited to, the pursuit of hedonic wellbeing which can end up valorizing and triggering what are ultimately selfish forms of urban mobility. The use of sports utility vehicles (SUVs) and light utility vehicles (LUVs) in urban settings epitomizes the dilemma. Promoted and used because of the comfort, pleasure and security they provided to drivers and passengers, SUVs and LUVs make roads less safe for the pedestrians, cyclists, e-scooter users and so forth who encounter them. They also create more pollution and $\mathrm{CO}_{2}$ emissions than most other passenger vehicle classes (unless they are completely electrified) and have potentially major adverse impacts on the health and lives of people near and far (cf. Horrocks and Wilson, 2019). Addressing the effects that the promotion and pursuit of particular forms of wellbeing generates can help transport researchers to mitigate the risk of generating depoliticized outcomes and policy recommendations that may - indirectly and inadvertently - reduce the environmental and social sustainability of urban mobility.

Addressing those effects head-on also offers transport researchers a way of connecting with critical social science scholarship on wellbeing. That scholarship is highly diversified in terms of theoretical basis and substantive themes (Burnett, 2012; Frawley, 2015; Smith, 2019), but two inter-related sets of insights are directly pertinent to transport research. Drawing on such scholarship can reduce the risks that research on the transport-wellbeing connection remains wedded to limited perspectives on what drives human action and narrow understandings of human beings. These claims may seem far-fetched but reflect that " $\mathrm{t}] \mathrm{heories}$ of wellbeing or quality of life cannot be disengaged from theories of what it is to be human and what life is for" (Scott, 2012, page 16). Examining the connections between transport and wellbeing means engaging in politics and practising philosophy.

Once we pause to reflect on the assumptions about human action that underpin the hedonic tradition of examining wellbeing, we can see that they are surprisingly one-dimensional and deterministic: human beings are taken to act, all else equal, in ways that enhance - if not optimize or even maximize - their own pleasure or satisfaction. This teleological structure is made possible by two underlying assumptions, which also underpin the work of eudaimonic psychologists.

The first assumption relates to the purported existence of universal and stable affective and cognitive states that can objectively be classified as positive or negative. This belief has been criticized in multiple ways. Anthropologists, geographers and others have convincingly argued that emotions and cognitions are both neuro-chemical processes and linguistically and culturally constituted (Frawley, 2015). Some psychologists are making similar claims (Gendron et al., 2020, page 13): 
"[I]nstances of emotion are emergent products of multiple biologically-evolved mechanisms that depend on cultural learning. We specifically propose that the developing brain bootstraps embodied concepts into its wiring, creating an internal model for how to best regulate the body across a range of situations within the constraints of a culturally-shaped world ... This embraining of culture may allow people to survive and thrive as a social species in a wide variety of contexts."

A related argument is that the identification of certain affective and cognitive states as positive is a normative process, with non-innocent consequences. For Burnett (2012), that identification needs to be seen as emerging from a series of changes in the nature and organization of capitalism in the Anglo-American world over the $20^{\text {th }}$ and $21^{\text {st }}$ century, which have embedded a neo-liberal 'tyranny of positivity' (Frawley, 2015), first in countries such as the USA and UK and increasingly across the planet. Thus, people are expected to feel good and be positive, and work on themselves if they don't - for instance, by making better choices - if they wish to avoid being blamed for their own 'ill-being'. In the transport context the normative working of the classification of affects and cognitions as positive or negative is a decidedly mixed bag with unavoidably context-specific consequences: the association of, say, driving with security may make some people reluctant to shift to other modes of transport - often with adverse consequences for the environment and those without access to cars - whereas it may make others consider forms of transport that offer a more direct relation with the traversed urban environment (e.g. walking, cycling or bus).

The implication is that both hedonic and eudaimonic scholarship on wellbeing is prescriptive rather than descriptive, making claims that - critics contend - are not universally true but ethnocentric (Christopher and Hickinbottom, 2008). The teleological logics they assume and promote are ultimately contingent and but one possibility among many, even if they may hold particular attraction in situations of "high levels of instability, insecurity, uncertainty, or economic misfortune" (Cabanas, 2018, page 13).

The second assumption is the idea that human beings are individuals with innate needs that pre-exist their expression and are independent from place, time and culture. This idea underpins Ryan et al.'s (2008) self-determination theory and has informed multiple studies on the transport-wellbeing connection (Abou-Zeid and Ben-Akiva, 2012; Singleton and Clifton, 2019). Yet, once non-western thinking on the nature of wellbeing and the individual is considered, the historical-geographical contingency of the belief in a priori needs becomes apparent. Thinking with roots in Africa, Asia, Latin America and Caribbean, or by indigenous peoples in countries like New Zealand or Canada is informative here. Consider Daoist and Buddhist thought, for instance. Daoism's highly influential Zhuangzi text teaches that the self is not contained in the individual body and spirit but part of a much larger unified whole (Tiwald, 2015), while the South Asian Mahāyāna approach to Buddhism holds that "there is no self in the sense of being a distinct entity with identity through time (and related to this, the Mahāyāna teaching that all things are empty of an inherent nature)" (Gowans, 2015, page 71).

While non-western thinking can open up exciting avenues for rethinking the relationships among wellbeing, needs and transport, strands of Euro-American thought have also challenged the assumptions of stable and objectively classifiable cognitive and affective status and universal, a priori needs. American pragmatism, feminist and queer theory and Deleuzian thought (influenced by the writings of Gilles Deleuze and Félix Guattari), among others, can open up new ways to thinking about the transport-wellbeing connection, especially if combined with ideas from non-Western philosophies. Despite important differences, all these modes of thinking share a commitment to eschewing essentialism (the idea that there is an 
inherent nature to humans or any other object) and foregrounding relationalism and contextuality (meaning that understandings of wellbeing, needs and the nature of the human being are dependent on the time, place and situation in which they emerge).

\section{SOME INITIAL PROPOSITIONS}

There can be no 'one-size-fits-all' anti-essentialist and relational perspective on the relationships between wellbeing and transport. Particular approaches and ideas will work better in some circumstances and places than in others. Nevertheless, based on participation in various research projects, including the one for which Pedro was interviewed, I believe that a given perspective will generate more useful and interesting insights if it meets at least two criteria. First is the replacement of a static and decontextualized teleology (maximize pleasure, pursue wisdom, achieve environmental mastery, etc.) with a focus on the processes through which desirable qualities and goals worth pursuing emerge out of - and co-evolve with - actions, experiences and (social) learning in particular social collectives, places and spaces. The nature of a good life and ways to achieve it are constantly becoming, worked out iteratively in doings and dialogues by and with social collectives in particular places, and conditioned by ideas and practices from elsewhere and the past. Secondly, if actions and the associated experiences and learning are key to both the conception or character of wellbeing and the relationship of wellbeing with transport, then it is important to give due consideration to the potential for action, or capabilities (Sen, 1993; see also Nussbaum, 2011). Such a focus can generate a great deal of insight into how the good life and its relationship with transport come to be understood in particular communities, times and places. Much more ought to be said about these criteria but there is only space for some illustrative remarks here.

Interest in the capabilities concept has increased markedly in transport research in the past decade (e.g. Beyazit, 2011; Hickman et al., 2017; Ryan et al., 2019; Schwanen and Nixon, 2020). These studies accept Sen's claim that wellbeing is about the positive freedom to achieve 'functionings', or activities and states of being, which individuals have reason to value, and focus on the conversion of capabilities, defined as real opportunities or potentials, into functionings. This conversion is mediated by all kinds of factors, from acquired skills and remembered experiences to policy outcomes, economic structures and discourses (Robeyns, 2017). This idea has significant implications for transport research because it means that simply providing resources or enhancing (person-based) accessibility - the ease of reaching destinations - is not enough to achieve functionings (see also Hickman et al., 2017). After all, what is the point of making bicycles available to individuals with a snazzy smartphone app or a Mobility-as-a-Service (MaaS) scheme if people have not learnt how to cycle, are discouraged by road designs that privilege vehicular transport, or cannot afford a digital payment system?

Nonetheless, there are multiple risks associated with the translation of the Capability Approach (CA) into transport research, due to both their original formulation within Amartya Sen's liberal-individualist framework and the habits of the research communities within which they are appropriated. Especially when adopted under a Euro-American eudaimonic psychology framing of human action and wellbeing in transport research, CA studies on transport can consolidate a narrow individualistic perspective on (and an a priori, externally determined conception of) wellbeing. This tendency is reinforced by the fact that much CA research ignores the interrelatedness and relational constitution of capabilities. One consequence of this is that enhancement of the capabilities of person $A$ or group $X$ to undertake certain travel may come at the expense of the capabilities of $B$ or $Y$ - a connection that undergirds many forms of (distributional) injustice in urban transport and one that transport research should help to diminish and avoid. 
A dynamic, relational and anti-essentialist perspective on capabilities in relation to urban mobility is certainly possible (Schwanen and Nixon, 2020). Mapping Kaufmann's (2002) concept of motility and its constituent elements of access (the set of available mobilities), competencies (abilities that make particular mobilities possible) and appropriation (turning access and competencies into action) onto Sen's capabilities is useful in this context, but all the invoked terms need to be understood as precarious achievements, constituted relationally and through actions, and possibly diminished or annulled if circumstances change (Schwanen and Nixon, 2020).

This is where returning to Pedro is useful. His neighborhood jogging scheme opened up opportunities to move and experience the 'suburbs' (access) and allowed novices to build up their fitness, skills and confidence (competencies) through its do-it-yourself/do-it-together approach. The appropriation of those capabilities and consequent turning them into functionings by participants generated capabilities for others - the communities whose neighborhoods become more secure, as well as for Pedro the opportunity to make his nephews and children proud. The merit of his scheme, then, is to put in place a tapestry of capabilities for a wide array of people and make conversion of those capabilities into functionings more likely. This merit derives from his scheme (and other cycling and walking groups, bike maintenance workshops, cycle lane improvement, etc. initiatives we studied) acting as a commons. Informed by critical geography scholarship (e.g., Chatterton, 2010), I use this term to denote a configuration of practices (functionings) that brings different people together in a cooperative spirit and turns an initially inhospitable urban environment - because it is unsafe for many and strongly cardependent - into a place where new capabilities and functionings are cultivated, also for more vulnerable residents of the 'suburbs'. The scale of the generated capabilities should not be exaggerated and their creation is dependent on the scheme's continuation, which is never guaranteed - a findings that held for most of the studied community initiatives to support walking and cycling. It nonetheless provides a pathway to a better life for at least some through changes in how people move around the city.

It should be noticed that few assumptions are made in the above discussion about the nature of human actions or human beings. While Pedro's words at the start of this chapter may suggest that he acted on the basis of a predetermined plan or set of goals, this seems more an artifact of how interviews as research method often induce post-hoc rationalization than a reflection of how his scheme evolved. Other parts of the interview suggest that goals emerged from doings and practical experimentation was worked out iteratively, dialogically and in an evolutionary manner. That manner is perhaps best qualified as 'agapistic', after pragmatist philosopher Charles Peirce's evolutionary understanding of agape. The notion of agape is understood in many different ways (Oord, 2005) but for Peirce (1983, page 179) is summed up in the 'golden rule' of "[s]acrific[ing] your own perfection to the perfectionment of your neighbor". For Peirce this was not a predetermined principle to be implemented by decontextualized individuals. It rather was a rule that could emerge in, and direct, evolutionary processes in the cosmos or the whole of which (individual) human beings are only one part. $\mathrm{He}$ called the resulting form of evolution agapasm and favored it over others, including the Darwinian variety premised on chance and greed, because he considered it a creative love that enhanced value for the whole during its evolution. I do not wish to generalize from Pedro's scheme and the other community-led initiatives to support walking and cycling that were studied to urban transport and cities in general. Nonetheless, the notion of agapasm aids our understanding of how the commons-producing initiatives, over time, generate capabilities and functionings that open up a better life for the many in the places affected by the schemes. 


\section{CONCLUSIONS}

If transport research is to contribute to the creation of sustainable, just and human-scale cities for all, then it needs to allow for multiple imaginings of what wellbeing is and how it can be achieved. It also needs to critically reflect on the effects generated by the pursuit of particular versions of wellbeing through travel behaviour and policies. This does not mean that research should stop working with hedonic conceptions or ideas from eudaimonic psychology, for these can be useful and insightful. They are, however, only two possibilities that come with a complex back-story within and outside academia, are culturally specific, and have normative consequences when used in empirical studies and stakeholder engagement. They should not be assumed to be universally applicable across the planet or to every social group in a particular place. Their applicability across space, time and culture needs to be ascertained, and effects of their use critically interrogated.

Transport research can benefit from experimenting with other, more context-sensitive and relational perspectives on wellbeing and human action. The ideas in the previous section begin to outline one option in this direction. Requiring further development, they build on earlier engagement with the Capability Approach in transport research and recognize the unavoidably social and interrelated nature of emergent capabilities and the functionings they enable. The ideas are also avowedly normative in their grounding in the notion that the capabilities enjoyed by some should not diminish those available to others near and far, in space and time. Not only should transport policy and urban planning promote walking and cycling as the default forms of transport and plan cities accordingly, or discourage the selfish hedonism of SUVs. They should also avoid that (physical) interventions that help to normalise walking and cycling in particular sites do not, say, raise land values and enhance gentrification dynamics that displace poor and otherwise vulnerable households from their residences, or that assume all pedestrians to be able-bodied and cyclists to be literate and have access to a smartphone or digital payment system. Truly sustainable transport in human-scale cities requires recognition of the relationally constituted tapestry of movement capabilities in particular places and across space and time.

\section{ACKNOWLEDGEMENTS}

This chapter draws on the DePICT (Designing and Policy Implementation for encouraging $C$ ycling and walking Trips) research project, funded by the Economic and Social Research Council (grant ES/N011538/1). I am grateful to Dr Denver Nixon, Hellem Miranda, and the research participants.

\section{REFERENCES}

Abou-Zeid, M. and Ben-Akiva, M. (2012) Well-being and activity-based models. Transportation 39 (6), 1189-1207.

Agamben, G. (2016) The Use of Bodies. Stanford, CA: Stanford University Press.

Aristotle (2009[n.d.]) The Nicomachean Ethics, translated by D. Ross. Oxford: Oxford University Press. 
Beyazit, E. (2011) Evaluating social justice in transport: lessons to be learned from the capability approach. Transport Reviews 31 (1), 117-134.

Burnett, S. (2012) The Happiness Agenda: A Modern Obsession. Basingstoke: Palgrave Macmillan.

Cabanas, E. (2018) Positive Psychology and the legitimation of individualism. Theory \& Psychology 28 (1), 3-19.

Chatterton, P. (2010) Seeking the urban common: furthering the debate on spatial justice. City $14(6), 625-628$.

Chatterjee, K., Chng, S., Clark, B., Davis, A., et al. (2020) Commuting and wellbeing: a critical overview of the literature with implications for policy and future research. Transport Reviews 40 (1), 5-34.

Christopher, J.C. and Hickinbottom, S. (2008) Positive Psychology, ethnocentrism, and the disguised ideology of individualism. Theory \& Psychology 18 (5), 563-589.

Cuignet, T., Perchoux, C., Caruso, G., Klein, O., et al. (2020) Mobility among older adults: Deconstructing the effects of motility and movement on wellbeing. Urban Studies 57(2) 383401.

Cutler, S.J. (1975) Transportation and changes in life satisfaction. The Gerontologist 15 (2), 155-159.

Curry, G., Richardson, T., Smyth, P., et al. (2010) Investigating links between transport disadvantage, social exclusion and well-being in Melbourne-Updated results. Research in Transportation Economics 29(1), 287-295.

De Vos, J., Schwanen, T., Van Acker, V. and Witlox, F. (2013) Travel and subjective wellbeing: A focus on findings, methods and future research needs. Transport Reviews 33 (4), 421-442.

De Vos, Mokhtarian, P.L., Schwanen, T., et al. (2016) Travel mode choice and travel satisfaction: bridging the gap between decision utility and experienced utility. Transportation 43 (5), 771-796.

Diener, E. (Ed.) (2009) The Science of Well-Being: The Collected Works of Ed Diener. Dordrecht: Spring.

Dobson, R., Dunbar, F., Smith, C.J, et al. (1978) Structural models for the analysis of traveler attitude-behavior relationships. Transportation 7 (4), 351-363.

Ettema, D.F., Gärling, T., Eriksson, L., Friman, M., Olsson, L.E. and Fuiji, S. (2011) Satisfaction with travel and subjective well-being: Development and test of a measurement tool. Transportation Research Part F: Traffic Psychology and Behaviour 14 (3), 167-175.

Frawley, A. (2015) Happiness research: an overview of critiques. Sociology Compass 9 (1), 6277.

Gärling, T. (2018) Travel and feelings, in: M. Friman, D. Ettema and L. Olsson (Eds.) Quality of Life and Daily Travel, pp. 41-56. Cham: Springer. 
Gendron, M., Hoemann, K., Crittenden, A.N., et al. (2020) Emotion perception in Hadza hunter-gatherers. Scientific Reports 10, 3867.

Gowans, C.W. (2015) Buddhist understandings of well-being, in: G. Fletcher (Ed.) The Routledge Handbook of Philosophy of Well-being, pp. 70-80. Abingdon: Routledge.

Hickman, R., Cao, M., Lira, B.M., et al. (2019) Understanding capabilities, functionings and travel in high and low income neighbourhoods in Manila. Social Inclusion 5 (4), 161-174.

Horrocks, J. and Wilson, N. (2019) "Beasts" - New Zealand's utility vehicles: their climate change emissions and macho marketing. New Zealand Medical Journal 132 (1507), 90-99.

Ingvardson, J., Kaplan, S., de Abreu e Silva, J., et al. (2019) Existence, relatedness an growth needs as mediators between mode choice and travel satisfaction: evidence from Denmark. Transportation 47 (1), 337-358.

Kahneman, D., Wakker, P.P. and Sarin, R. (1997) Back to Bentham? Explorations of experienced utility. Quarterly Journal of Economics 112 (2), 375-405.

Kasser, T., Cohn, S., Kanner, A.D., et a;. (2007) Some costs of American corporate capitalism: a psychological exploration of value and goal conflicts. Psychological Inquiry 18 (1), 1-22.

Kaufmann, V. (2002) Re-thinking Mobility. Aldershot: Ashgate.

Le, H.T.K. and Carrel, A.L. (2019) Happy today, satisfied tomorrow: emotion-satisfaction dynamics in a multi-week transit user smartphone survey. Transportation in press.

Lucas, K. (2012) Transport and social exclusion: Where are we now?. Transport Policy 20, 105-113.

Moktharian, P.L. (2019) Subjective well-being and travel: retrospect and prospect. Transportation 46 (2), 493-513.

Morton, C., Caulfield, B. and Anable, J. (2016) Customer perceptions of quality of service in public transport: Evidence for bus transit in Scotland. Case Studies in Transport Policy 4 (3), 199-207.

Nussbaum, M.C. (2011) Creating Capabilities. Cambridge, MA: Harvard University Press.

Oord, T.J. (2005) The love racket: defining love and agape for the love-and-science research program. Zygon 40 (4), 919-938.

Pas, E.I. and Koppelman, F.S. (1986) An examination of the determinants of day-to-day variability in individuals' urban travel behavior. Transportation 13 (2), 183-200.

Peirce, C.S. (1983) Evolutionary love. The Monist 3 (2), 176-200.

Recker, W.W. and Golob, T.F. (1976) An attitudinal modal choice model. Transportation Research 10 (5), 299-310.

Richins, M. (2017) Materialism pathways: the processes that create and perpetuate materialism. Journal of Consumer Psychology 27 (4), 480-499. 
Robeyns, I. (2017) Wellbeing, Freedom and Social Justice: The Capability Approach Reexamined. Cambridge: Open Book Publishers.

Ryan, J., Wrestrand, A., Schmidt,, S.M. (2019) Disparities in mobility among older people: findings from a capability-based travel survey. Transport Policy 79, 179-192.

Ryan, R.M., Huta, V. and Deci, E.L. (2008) Living well: a self-determination theory perspective on eudaimonia. Journal of Happiness Studies 9 (1), 137-170.

Ryff, C. and Singer, B.H. (2008) Know thyself and become what you are: a eudaimonic approach to psychological well-being. Journal of Happiness Studies 9 (1), 13-39.

Schwanen, T. and Nixon, D.V. (2020) Understanding the relationships between wellbeing and mobility in the unequal city, in: M. Keith and A.A. De Souza Santos (Eds.) Urban Transformations and Public Health in the Emergent City, pp. 79-101, Manchester: Manchester University Press.

Scott, K. (2012) Measuring Wellbeing: Towards Sustainability? London: Routledge.

Sen, A. (1993) Capabilities and wellbeing, in: M. Nussbaum and A, Sen (Eds.) The Quality of Life, pp. 30-53. Oxford: Clarendon Press.

Singleton, P.A. (2019) Walking (and cycling) to well-being: modal and other determinants subjective well-being during the commute. Travel Behaviour and Society 16, 249-261.

Singleton, P.A. and Clifton, K. (2019) Towards measures of affective and eudaimonic subjective well-being in the travel domain. Transportation, in press.

Smith, T.S.J. (2019) Sustainability, Wellbeing and the Posthuman Turn. Cham: Palgrave Macmillan

Teixeira, I., Rodrigues da Silva, A.N., Schwanen, T., et al. (2020) Does cycling infrastructure reduce stress biomarkers in commuting cyclists? A comparison of five European cities. Journal of Transport Geography 88, 102830.

Tiwald, J. (2015) Well-being and Daoism, in: G. Fletcher (Ed.) The Routledge Handbook of Philosophy of Well-being, pp. 56-69. Abingdon: Routledge.

Vella-Brodrick, D.A. and Stanley, J. (2013) The significance of transport mobility in predicting well-being. Transport Policy 29, 236-242.

Waterman, A.S. (1993) Two conceptions of happiness: contrasts of personal expressiveness (eudaimonia) and hedonic enjoyment. Journal of Personality and Social Psychology 64 (4), 678-691. 